\title{
n-GaAs BAND-EDGE REPOSITIONING BY MODIFICATION WITH METALLOPORPHYRIN/POLYSILOXANE MATRICES ${ }^{\dagger}$
}

\author{
HIKMAT S. HILAL*, MOAYYAD MASOUD, SAMAR SHAKHSHIR \\ and NAJEH JISRAWI \\ Department of Chemistry, An-Najah N. University, Nablus, PO Box 7, West Bank, Palestine
}

(Received 2 October 2001; In final form 6 November 2001)

\begin{abstract}
Tetra(-4-pyridyl)porphyrinatomanganese(III)sulfate, $\mathrm{MnP}$, (in the forms of $\mathrm{Mn}^{\mathrm{III}}$ and $\mathrm{Mn}^{\mathrm{II}}$ mixture), was embedded into a polysiloxane polymer matrix and attached to the surfaces of $n-G a A s$ wafers. The $n-G a A s /$ polymer/MnP system was annealed under nitrogen and used for photoelectrochemical study in water $/ \mathrm{LiClO} 4 / \mathrm{Fe}(\mathrm{CN})_{6}^{3-} /$ $\mathrm{Fe}(\mathrm{CN})_{6}^{4-}$ system. The results indicated a positive shift in the value of the flat-band potential of the semiconductor due to MnP. This was manifested by shifting the values of the dark-current onset potential and the photo-current open-circuit potential towards more positive values. These findings are potentially valuable in future applications of solar energy in hydrogen and oxygen production from water.
\end{abstract}

Keywords: Band-edge positions; Polysiloxane; Metalloporphyrin; Modification; n-GaAs; Photoelectrochemistry; Semiconductor

\section{INTRODUCTION}

Monocrystalline semiconductor electrodes are known catalysts for conversion of light into electric and chemical energies [1-7]. Controlling the semiconductor characteristics at the solid/liquid interface, associated with PEC studies, is one potentially important objective. Shifting the positions of the flat-band potential is important for photoelectrochemical (PEC) applications, viz. the position of the conduction band (CB) and the valence band (VB) edges determines the energetics and kinetics of charge transfer at the solid/liquid interface. This in turn will affect the ability of the semiconductor surface to oxidize or reduce other chemicals in contact with it. For example, n-GaInP ${ }_{2}$ needs about $300 \mathrm{mV}$ lowering in its flat-band potential, in order to effectively oxidize water [4]. It is assumed that shifting the flat-band potentials of a given semiconductor (SC) can be achieved by attaching charged ions to its surface. Positive charges may cause a positive shifting (lowering) in the value of the flat-band potential. This is due to the stabilization of the molecular orbitals within a given energy band by the neighboring positive charges. However, if the positive charges are

\footnotetext{
* Corresponding author. Fax: +(972)-9-2387982; E-mail: hikmathilal@yahoo.com/hshilal@najah.edu

${ }^{\dagger}$ This paper has been presented before the Sharjah Solar Energy Conference, University of Sharjah, Feb. 117-21, 2001, and accepted to the proceedings.
} 
attached only to the surface, the lowering will occur only in the Space Charge Layer, SCL, and will mostly involve the flat-band potential $\left(V_{\mathrm{fb}}\right)$. Scheme (I) shows how attachment of cations, to a SC surface, may lower its $V_{\mathrm{fb}}$ values. The Scheme also shows how such lowering will kinetically enhance hole transfer from the VB accumulation region to the other species with oxidation potentials slightly lower than the unmodified VB $V_{\mathrm{fb}}$ level. On the other hand, negative charges should yield a negative shifting (destabilizing) in the band-edge positions.

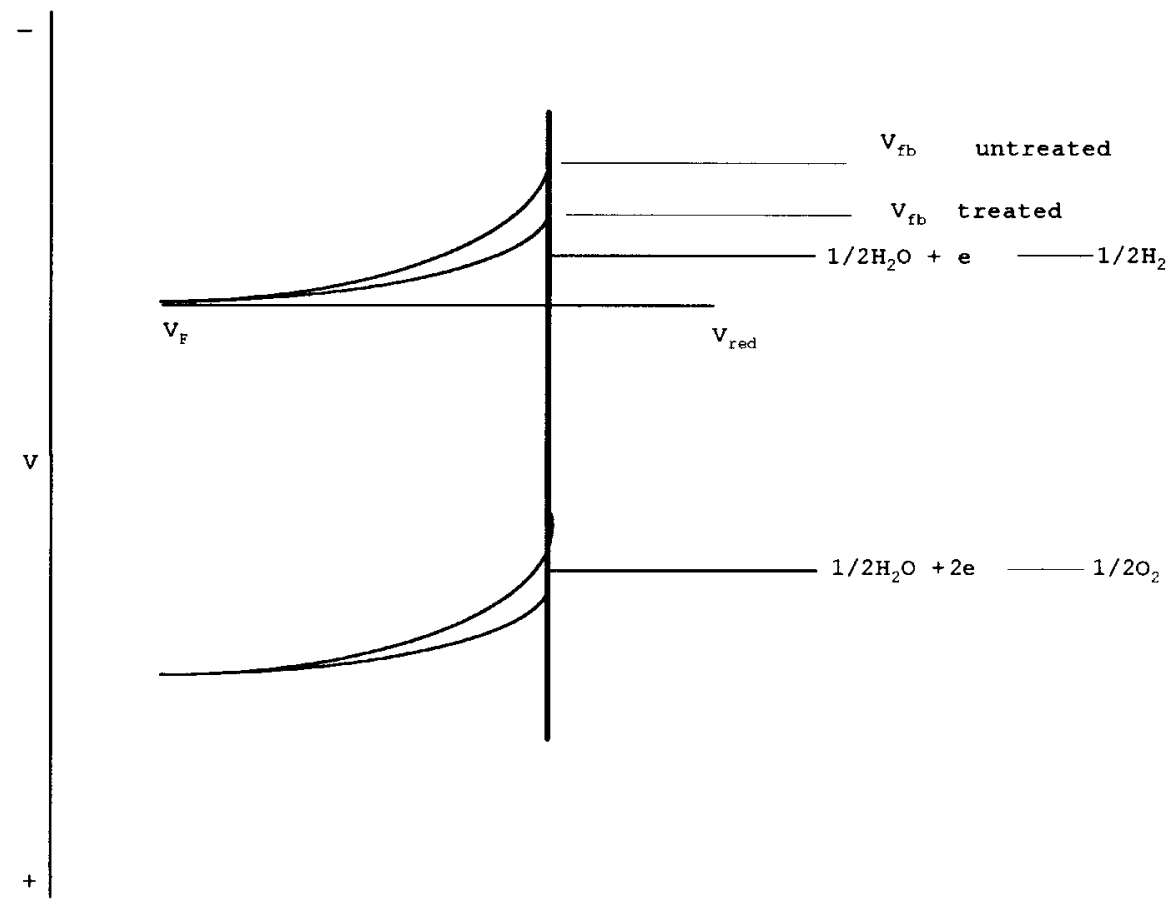

SCHEME 1

In earlier studies, we have modified $\mathrm{n}-\mathrm{GaAs}$ and $\mathrm{n}-\mathrm{GaInP}_{2}$ with $\mathrm{MnP}$ cations, at a submonolayer coverage level, by chemically attaching metalloporphyrines onto the SC surface through an anchoring ligand via a quaternization reaction [3]. It was found that the $\mathrm{MnP}$ cations shifted the positions of the SC flat-band positions towards more positive values. However, the earlier technique did not resolve the technical difficulties associated with the peeling out of the monolayer coverage.

The main goal of this work is to permanently control the n-GaAs band-edge positions at the solid/liquid interface in PEC systems. n-GaAs was chosen here for investigation purposes as a model SC. Future works will follow using n-GaInP 2 and other SC materials, which are good candidate photocatalysts for light-driven water splitting into hydrogen and oxygen.

\section{EXPERIMENTAL}

\subsection{Materials}

$\mathrm{LiClO}_{4}, \mathrm{~K}_{3} \mathrm{Fe}(\mathrm{CN})_{6}, \mathrm{~K}_{4} \mathrm{Fe}(\mathrm{CN})_{6}$, and the 5,10,15,20-tetra(-4-pyridyl)-21H,23H-porphine, $\left(\mathrm{H}_{2} \mathrm{TPy}\right)$, were purchased from Aldrich. The MnP complex mixture was prepared from $\mathrm{H}_{2}$ TPyP as described in the literature [8]. The mixture contained complexes of both the 
$\mathrm{Mn}^{\mathrm{II}}$ and the $\mathrm{Mn}^{\mathrm{III}}$, as depicted from the electronic absorption spectra in the visible region. Indiumtinoxide (ITO) was purchased from Delta Technologies, Ltd. as one-side coated $1.5 \mathrm{~mm}$ thick transparent glass, with $100 \Omega$ /square. Mono-crystalline single surface mirror polished Si-doped $\left(3.2 \times 10^{17} \mathrm{~cm}^{-3}\right.$ for the front and $9.9 \times 10^{17} \mathrm{~cm}^{-3}$ for the tail) $\mathrm{n}$-GaAs wafers (Crystal Specialties, Intl.) were used. The monocrystalline plates, $50 \mathrm{~mm}$ roundshaped, were $0.35 \mathrm{~mm}$ thick with $\langle 100\rangle$ orientation. The mobility was $2.8 \times 10^{3} \mathrm{~cm}^{2} / \mathrm{V}-\mathrm{s}$ in the front and $2.3 \times 10^{3} \mathrm{~cm}^{2} / \mathrm{V}$-s in the tail. The wafer was cut into smaller wafers. Indium metal back contact was made as thin uniform layers. The wafers were then annealed at $350{ }^{\circ} \mathrm{C}$ under clean $\mathrm{N}_{2}$ atmosphere. The $\mathrm{SC}$ electrodes were fabricated as follows: the small square $\mathrm{n}$-GaAs wafer $\left(\sim 0.1 \mathrm{~cm}^{2}\right)$ was mounted to a copper plate (with a copper wire welded to it) using a thin uniform layer of Ga-In eutectic. The back-side and the edges of the electrode, together with the copper wire, were then insulated with an epoxy resin and allowed to dry overnight under nitrogen. The dried sealed electrodes were then rinsed repeatedly with methanol to remove any possible oily solvent contaminants.

Etching of the $\mathrm{n}-\mathrm{GaAs}$ window was conducted using a $\mathrm{Br}_{2} /$ methanol $(1.0 \% \mathrm{~V} / \mathrm{V})$ solution [9]. The electrode was dipped inside the etching solution for 5 seconds, immediately rinsed with de-ionized water and then with methanol. The electrode was then dried using nitrogen stream.

\subsection{Electrode Modification}

The etched SC electrode surface was then modified as follows: A dilute solution of the commercial, R.T.V. polysiloxane $\left(-\mathrm{O}-\mathrm{SiR}_{2}-\mathrm{O}-\right)_{\mathrm{n}}$ (vended as a paste in acetic acid), was prepared by dissolving $0.05 \mathrm{~g}$ of the paste in $100 \mathrm{~mL}$ of dichloromethane. Similarly, methanol solutions of $\mathrm{MnP}\left(0.1 \mathrm{~g}, 1.38 \times 10^{-4} \mathrm{~mol}\right.$, in $\left.10 \mathrm{~mL}\right)$ were prepared. The MnP/ Polysiloxane solutions were prepared by adding the MnP solution to the Polysiloxane solution, in a $1: 4 \mathrm{~V} / \mathrm{V}$ ratio, respectively. $0.1 \mathrm{~mL}$ of the stock solution (containing $4 \times 10^{-5} \mathrm{~g}$ polysiloxane and $2 \times 10^{-4} \mathrm{~g} \mathrm{MnP}$ ) were pipetted onto the $\mathrm{n}$-GaAs polished surface. The organic solvents were then allowed to evaporate, leaving a transparent thin layer of the $\mathrm{MnP} /$ Polysiloxane matrix on the SC surface. The polymer matrix was calculated to be $4.0 \mu \mathrm{m}$ thick, containing $2.0 \times 10^{-4} \mathrm{~g}$ of $\mathrm{MnP}$ (its concentration in the matrix being $6.9 \mathrm{mmol} / \mathrm{cm}^{-3}$ ). With thicker films, the polymer matrix was insulator and allowed no current to be measured. Therefore, unless otherwise stated, all experiments were conducted using the $4.0 \mu \mathrm{m}$ thickness MnP/Polysiloxane coated n-GaAs after annealing under nitrogen.

\subsection{Equipment}

Solid-state electronic absorption spectra were measured on a Shimadzu UV-1601 spectrophotometer, as solid thin films of $\mathrm{MnP} /$ Polysiloxane on quartz slides. The Soret band at $\sim 460 \mathrm{~nm}$ resembled literature values for other $\mathrm{MnP}$ spectra measured in solid state [8] and in solution [10]. Infra-red spectra was measured, as thin films of MnP/Polysiloxane, on a Shimadzu FTIR-8201 PC spectrophotometer. Current-potential measurements were performed using a Princeton Applied Research (PAR) Model 263A computer-controlled potentiostat. The Mott-Shottky plots were measured with a SRS 830 DSP lock-in amplifier, a SRS DS345 function generator and a PAR Model 263A potentiostat. All measurements were conducted in a thermostated one-compartment three-electrode electrochemical cell with SCE electrode, a platinum counter electrode and the SC working electrode. $\mathrm{LiClO}_{4}$ $(0.10 \mathrm{M})$ was used as a supporting electrolyte, and $\mathrm{Fe}(\mathrm{CN})_{6}^{3-/ 4-}\left(0.05 \mathrm{M} \mathrm{K} \mathrm{K}_{3} \mathrm{Fe}(\mathrm{CN})_{6}\right.$, $\left.0.05 \mathrm{M} \mathrm{K}_{4} \mathrm{Fe}(\mathrm{CN})_{6}\right)$ as a redox couple in freshly distilled water with (pH 6.5). A nitrogen gas stream was kept flowing above the solution, throughout the experiment, to minimize 
contamination with air. Illumination was carried out using a $50 \mathrm{~W}$ Xenon lamp equipped with a concentrating lens, placed at defined distance from the working electrode. A $10 \mathrm{~mm}$ thick water filter was placed between the lamp and the electrode. The intensity of light at the electrode surface was measured with a correlated light-meter and was $0.1013 \mathrm{~W} \mathrm{~cm}^{-2}$.

\subsection{Cyclic Voltammometric Measurements}

Cyclic voltammometry was measured on a PAR 263A potentiostat, in a one-compartment cell, using platinum electrodes, $\mathrm{SCE}$ electrode, in water $/ \mathrm{LiClO}_{4}$ under nitrogen atmosphere with a scanning rate of $100 \mathrm{mV} / \mathrm{s}$.

\subsection{Capacitance-Voltage}

Measurements of capacitance vs. applied potential were conducted using same electrochemical cell, described above, in water $/ \mathrm{LiClO}_{4} \mathrm{Fe}^{2+} / \mathrm{Fe}^{3+}$ system. Mott-Schottky M-S plots were constructed, for a potential scanning over a range of -0.5 to $+0.5 \mathrm{~V}$ ( $v s$. SCE) at a scan rate $100 \mathrm{mV} / \mathrm{s}$ and $10 \mathrm{kHz}$ frequency.

\section{RESULTS AND DISCUSSION}

The water $/ \mathrm{LiClO}_{4} / \mathrm{Fe}^{2+} / \mathrm{Fe}^{3+}$ systems are not the best solution for $\mathrm{n}-\mathrm{GaAs}$. They give poor current-potential $(J-V)$ plots, in the dark and under illumination. Researchers use alternative systems for the $J-V$ measurements of n-GaAs in aqueous media. $\mathrm{Se}^{2-} / \mathrm{Se}_{2}^{2-}$ redox couples are known to give better $J-V$ plots for n-GaAs electrodes. The water $/ \mathrm{LiClO}_{4} / \mathrm{Fe}^{2+} / \mathrm{Fe}^{3+}$ system was intentionally employed in this work, so as to see if the modification has any effect on the shapes of the n-GaAs $J-V$ plots. Figure 1 indicates that the attachment of the $\mathrm{MnP} /$ Polysiloxane matrix to the n-GaAs surface significantly enhanced the $J-V$ plots while using the $\mathrm{Fe}^{2+} / \mathrm{Fe}^{3+}$ redox couple system in water. This was attributed to the extra stabilization of the $n$-GaAs surface by the matrix. The modification method described here has a very important technical advantage over other ones described in the literature [6-7,11-17]. In other earlier reports, the SC surface was modified with conjugated polymeric matrices. The polymer layers were found to peel off. Efforts have been made to improve the adherence of the polymer to the SC surface. Researchers often scratch the n-GaAs polished surfaces to prevent the polymer matrix peeling. In this work, the polymer matrix was permanently adhered to the polished n-GaAs surface without any need for scratching. When the $\mathrm{n}-\mathrm{GaAs} / \mathrm{MnP} /$ Polysiloxane system was annealed at $100^{\circ} \mathrm{C}$ the adherence was enhanced and a clear robust glassy solid layer appeared on the surface. When thick matrices of $\mathrm{MnP} /$ Polysiloxane were used, the $J-V$ plots showed poor current readings, indicating that the matrix conductivity was low. Therefore, thin matrices were made to lower the resistance. Optimum matrix thickness was $4.0 \mu \mathrm{m}$. With such thickness, well-defined uniform $J-V$ plots were obtained.

\subsection{Dark-Current Measurements}

Dark $J-V$ plots were measured for the naked (etched), Polysiloxane-coated (n-GaAs/ Polysiloxane) and n-GaAs/MnP/Polysiloxane electrodes. Figure 1 shows that the MnP-modified SC surface (after annealing) has a shifting in the dark-current onset potential, $V_{\text {onset }}$, compared to the un-modified surface. The value of the shift was about $200 \mathrm{mV}$, towards a more positive potential value (positive shift). 


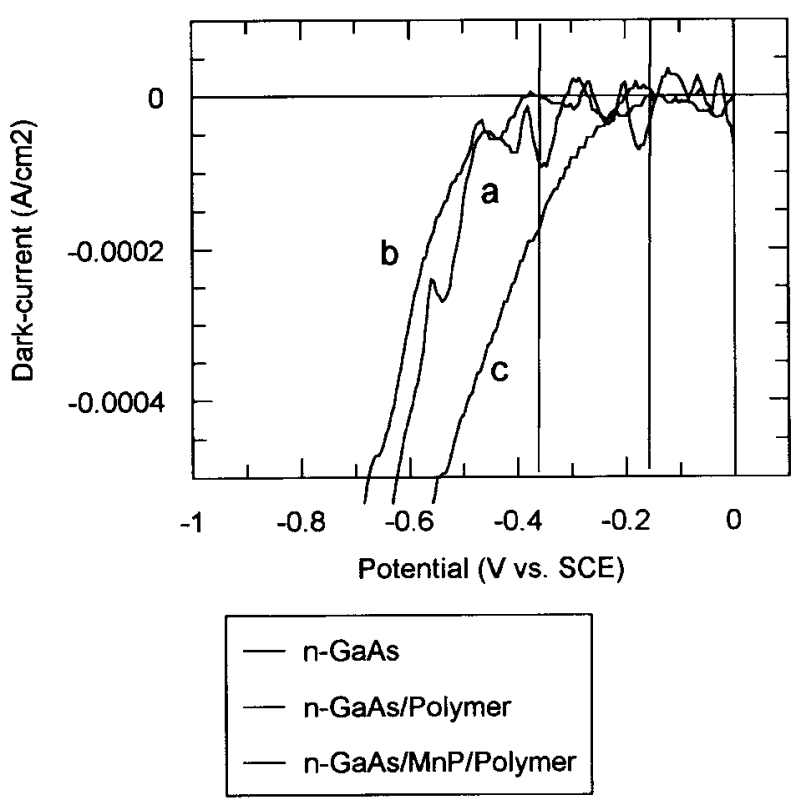

FIGURE 1 Dark-current $v$ s. potential plots measured for (a) unmodified n-GaAs, (b) polymer-modified n-GaAs and (c) $\mathrm{MnP} /$ polymer-modified $\mathrm{n}$-GaAs electrodes. All measurements were conducted in water $/ \mathrm{LiClO}_{4} /$ $\mathrm{Fe}(\mathrm{CN})_{6}^{3-} / \mathrm{Fe}(\mathrm{CN})_{6}^{4-}$ in the dark at $25^{\circ} \mathrm{C}$.

Such a positive shift is an indicator of a lowering in the value of the flat-band potential $\left(V_{\mathrm{fb}}\right)$. The lowering in the value of the $V_{\mathrm{fb}}$ dictates that only a less negative (more positive) applied onset potential is needed for the dark-current to occur, when using all other conditions the same. Scheme 2 describes how, in the dark, the value of the onset potential for the modified n-GaAs is less negative than that for the naked n-GaAs.

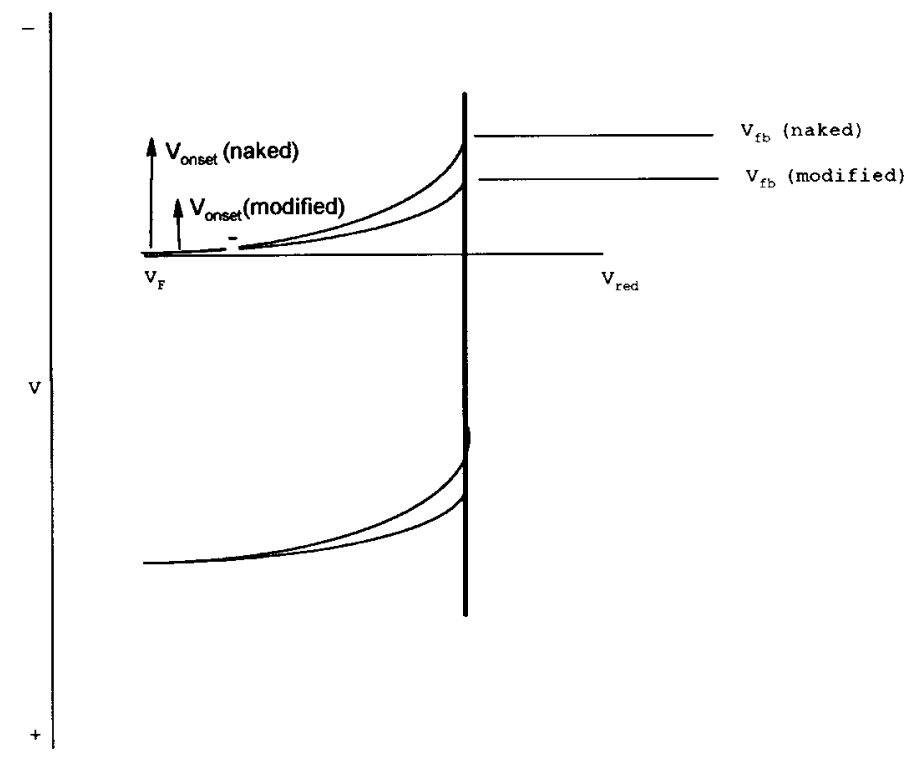


The lowering in the value of $V_{\mathrm{fb}}$ is mainly due to the MnP positive charges entrapped inside the polysiloxane matrix adhered to the SC surface. SC surfaces modified with MnP-free polysiloxane matrix did not show a lowering in the value of the $V_{\mathrm{fb}}$. This is because the polysiloxane matrix free of positive charges. The effect of solution ions on the position of $V_{\mathrm{fb}}$ has been reported [3-5, 18-19].

The $V_{\mathrm{fb}}$ lowering was well manifested in annealed n-GaAs/MnP/Polysiloxane electrode. With no annealing, no significant shifting in $V_{\mathrm{fb}}$ was observed. Therefore, and the annealing process is necessary to permanently bring the $\mathrm{MnP}$ positive ions into direct contact with the $\mathrm{SC}$ surface at the $\mathrm{SC} /$ matrix interface.

\subsection{Photo-Current Measurements}

The $J-V$ plots were measured for the modified and unmodified n-GaAs surfaces under high intensity polychromatic illumination with a Xe lamp, in the water $/ \mathrm{LiClO}_{4} / \mathrm{Fe}^{2+} / \mathrm{Fe}^{3+}$ system described above. Figure 2 shows that the annealed n-GaAs/MnP/Polysiloxane surfaces exhibited a shifting in the value of the open-circuit potential $V_{\mathrm{oc}}$ towards a more positive (lower) position. The $120 \mathrm{mV}$ lowering in the value of the $V_{\mathrm{oc}}$ is a good indication of a lowering in the value of the $V_{\mathrm{fb}}$. Such a lowering is due to the MnP positive charges in a close proximity to the SC surface. In the absence of MnP, no shifting in the value of the $V_{\mathrm{oc}}$ was observed. The
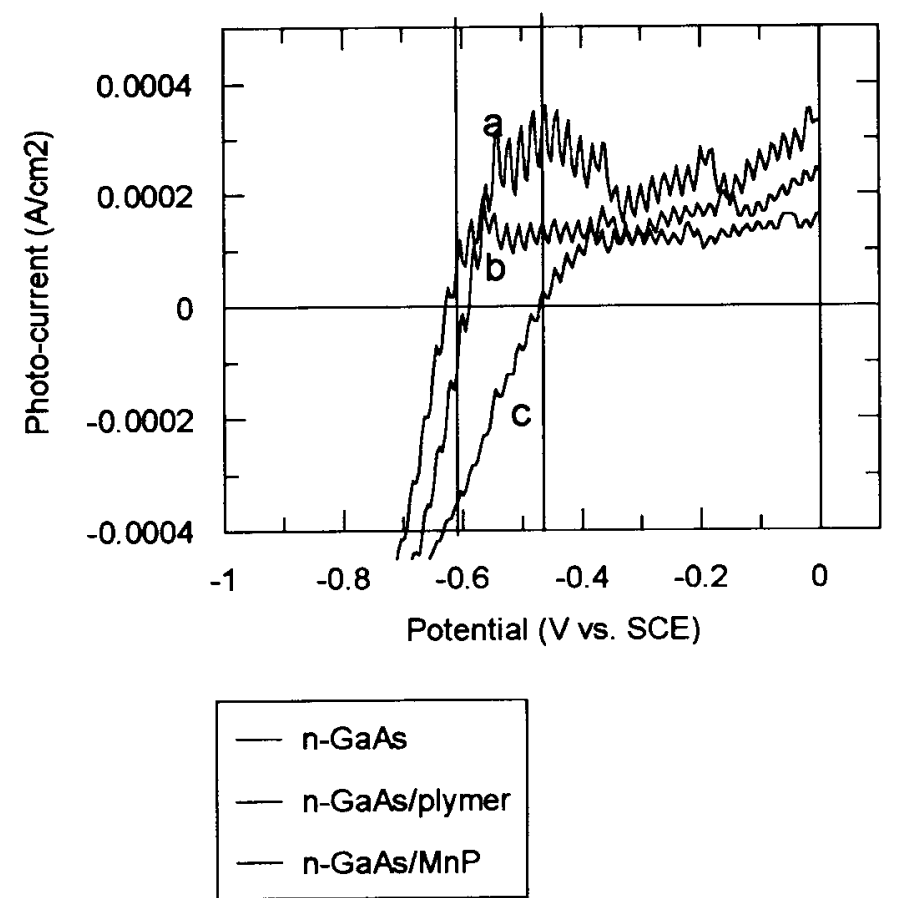

FIGURE 2 Effect of attachment of MnP/polymer on the photocurrent-potential characteristics for (a) unmodified n-GaAs, (b) polymer-modified n-GaAs and (c) Mn/polymer-modified n-GaAs electrodes. All measurements were conducted under illumination using a Xe lamp (illumination intensity at the electrode surface $0.1013 \mathrm{~W} \mathrm{~cm}^{-2}$ ) in water $/ \mathrm{LiClO}_{4} / \mathrm{Fe}(\mathrm{CN})_{6}^{3-} / \mathrm{Fe}(\mathrm{CN})_{6}^{4-}$ at $25^{\circ} \mathrm{C}$. 
lowering in the value of the $V_{\text {oc }}$ by attachment of positive charges has already been observed in similar photoelectrochemical systems [3] using sub-mono-layer of MnP chemically anchored to the SC surface. The positive shifting of the value of the SC $V_{\mathrm{oc}}$ by modification with positive charges is theoretically accepted. With modification, the band bending is lowered as a result of $V_{\mathrm{fb}}$ lowering (stabilizing). Therefore, a less negative (more positive) applied bias is therefore needed to flatten the bands, and consequently to inhibit the photocurrent, in case of the modified SC. The value of $V_{\mathrm{oc}}$ in case of modified SC will in fact be lowered (positively shifted) and will indicate a lowering in the value of the $V_{\mathrm{fb}}$.

The value of the lowering in the $V_{\text {oc }}$ is smaller than the value of the dark-current $V_{\text {onset }}$. This is not unexpected. Literature $[1-2,19]$ shows that exposure of naked SC electrodes, to light, causes a positive shift in the value of $V_{\mathrm{oc}}$ as a result of hole accumulation in the space charge region. Such positive charge accumulation would cause a shift in the value of the $V_{\mathrm{oc}}$.

\subsection{Capacitance Measurements}

Values of the $V_{\mathrm{fb}}$ were directly measured for the modified and the unmodified n-GaAs electrodes. Capacitance $(C)$ vs. potential $(V)$ plots were measured in water $/ \mathrm{LiClO} \mathrm{Cl}_{4} / \mathrm{Fe}^{2+} / \mathrm{Fe}^{3+}$ systems in the dark and under illumination. Mott-Schottky (M-S) plots of $C^{-2} v s . V$ were constructed in order to directly measure $V_{\mathrm{fb}}$ values [20-22].

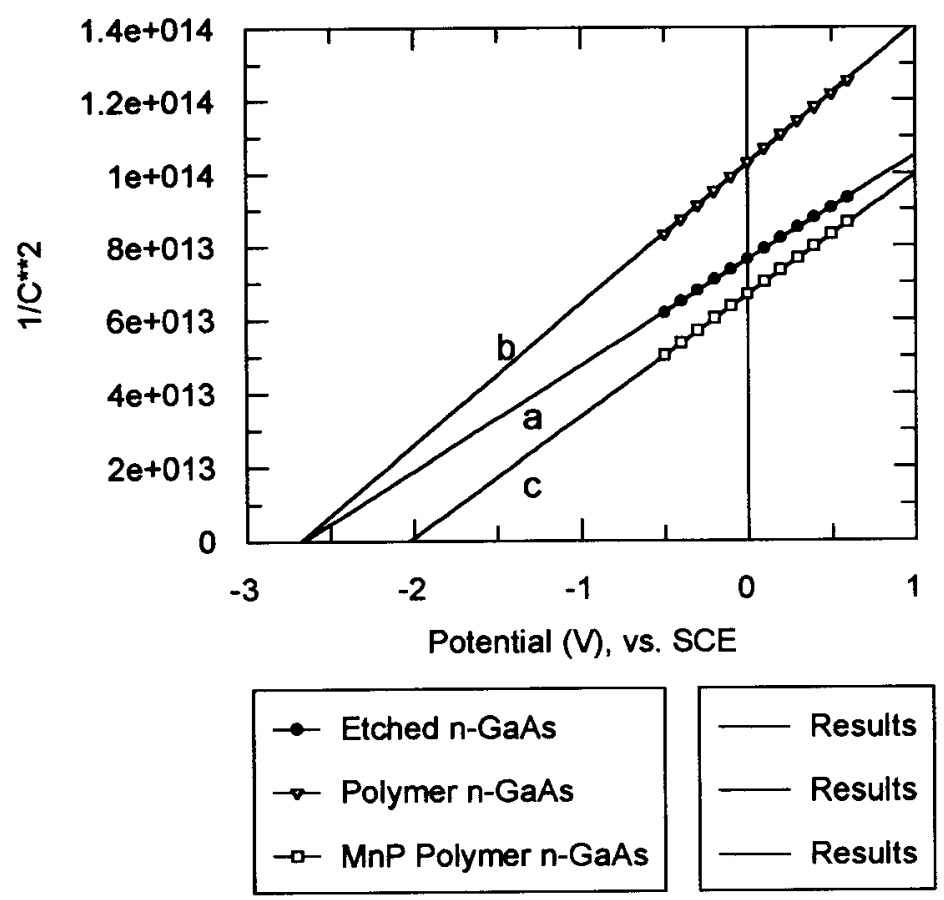

FIGURE 3 Effect of n-GaAs surface modification on the value of its flat-band potential, after annealing each electrode, using (a) unmodified, (b) polymer-modified and (c) $\mathrm{MnP} /$ polymer-modified electrodes. All measurements were conducted in the dark in water $/ \mathrm{LiClO}_{4} / \mathrm{Fe}(\mathrm{CN})_{6}^{3-} / \mathrm{Fe}(\mathrm{CN})_{6}^{4-}$ at $25^{\circ} \mathrm{C}$. 


\subsection{In the Dark}

Figure 3 shows the Mott-Schottky plots measured for the annealed modified and unmodified n-GaAs wafers. The value of $V_{\mathrm{fb}}$ in case of $\mathrm{n}-\mathrm{GaAs} / \mathrm{MnP} /$ Polysiloxane is shifted towards a more positive value, by up to $700 \mathrm{mV}$, relative to that of the unmodified n-GaAs. The attachment of the polymer, without MnP, did not cause positive shifting. These results indicate that the positive shift in the value of $V_{\mathrm{fb}}$ is a result of only MnP ions. Figure 4 shows M-S plots measured for the modified and unmodified n-GaAs electrodes without prior annealing. In the case of the non-annealed $\mathrm{n}-\mathrm{GaAs} / \mathrm{MnP} /$ Polysiloxane electrodes, the value of the $V_{\mathrm{fb}}$ was positively shifted by only about $240 \mathrm{mV}$. Again, with no $\mathrm{MnP}$, no shift in the value of the $V_{\mathrm{fb}}$ was observed.

Figures (3 and 4) show that annealing n-GaAs/MnP/Polysiloxane surfaces gives better interaction between the $\mathrm{SC}$ and the MnP. This was manifested by the larger shift in the $V_{\mathrm{fb}}$ value in case of annealing.

The $\mathrm{n}$-GaAs surface modification enhanced the SC surface in another way as appears from Figures (3 and 4). The slope of the modified $n-G a A s$ wafer gave a value for the measured doping density, DD, $\left(3.26 \times 10^{17} \mathrm{~cm}^{-3}\right)$ consistent with the authentic value $(3.26 \times$ $10^{17} \mathrm{~cm}^{-3}$ ) of the semiconductor. The un-modified surface showed rather less accurate values, ranging between $3.7 \times 10^{17}$ and $5.24 \times 10^{17} \mathrm{~cm}^{-3}$. The accuracy in the measured value of the $\mathrm{DD}$, for the modified $n-G a A s$ surface, is due to the added surface stability. The unmodified $n-G a A s$ degrades in the aqueous system $\mathrm{LiClO}_{4} / \mathrm{Fe}^{3+} / \mathrm{Fe}^{2+}$ employed here. The lack of the surface stability is presumably the reason for the inaccurate values of DD measured for the unmodified n-GaAs in the dark.

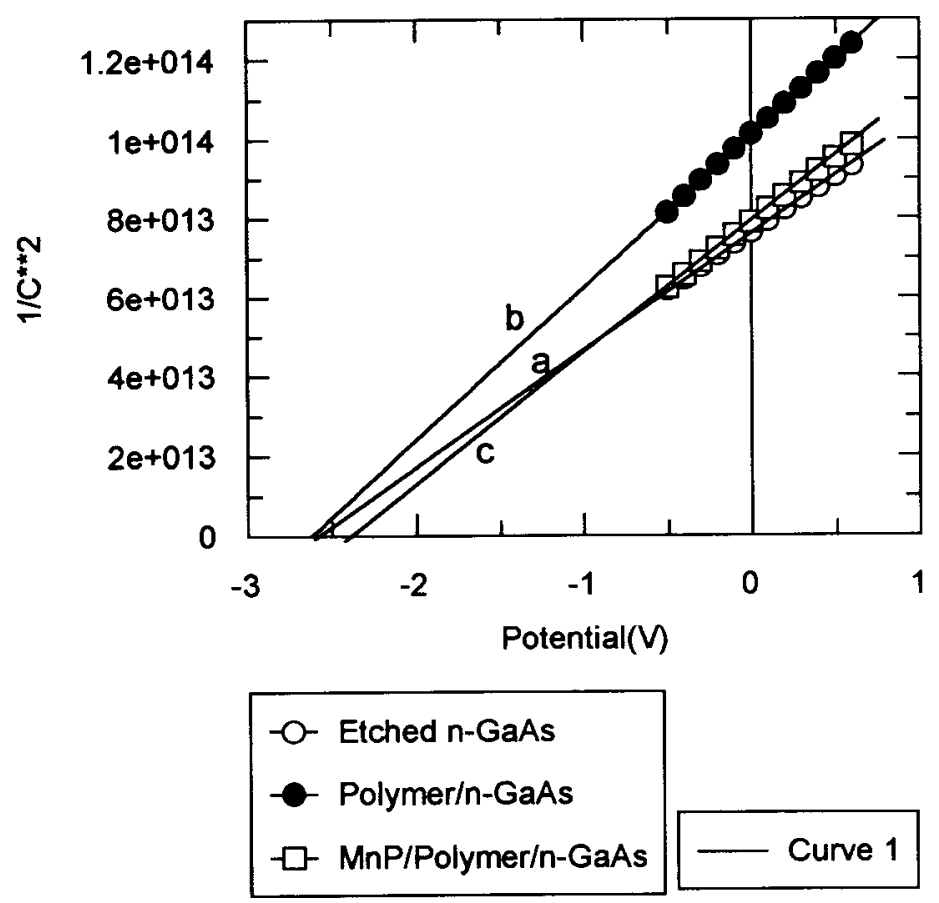

FIGURE 4 Effect of n-GaAs surface modification on the value of its flat-band potential, without annealing the electrodes, using (a) unmodified, (b) polymer-modified and (c) $\mathrm{MnP} /$ polymer-modified electrodes. All measurements were conducted in the dark in water $/ \mathrm{LiClO}_{4} / \mathrm{Fe}(\mathrm{CN})_{6}^{3-} / \mathrm{Fe}(\mathrm{CN})_{6}^{4-}$ at $25^{\circ} \mathrm{C}$. 


\subsection{Under Illumination}

M-S plots were measured for the modified and unmodified n-GaAs surfaces in the water $/ \mathrm{LiClO}_{4} / \mathrm{Fe}^{2+} / \mathrm{Fe}^{3+}$ system. The effect of $\mathrm{n}-\mathrm{GaAs}$ surface modification was more pronounced. The low stability of the unmodified n-GaAs surface made it difficult to measure the M-S plots under illumination. No linear M-S plots could be constructed for the unmodified surface. The Polysiloxane-modified surface was also not stable enough to show linear plots. Only did the annealed n-GaAs/MnP/Polysiloxane electrode show soundly linear M-S plots under illumination with room light, Figure 5. The non-annealed modified surface showed but to a lesser extent linear M-S plots, as shown in Figure 5.

\subsection{Cyclic Voltammometry}

Thin films of $\mathrm{MnP} /$ polymer were cast onto a pre-cleaned platinum gauze and used as a working electrode. This was to measure the cyclic voltammograms of the MnP inside the polysiloxane matrix. The oxidation peak at $(-100 \mathrm{mV})$ and the reduction peak at $(-230 \mathrm{mV})$, against SCE, were observed. These values are consistent with earlier values of MnP cation measured as homogenous solutions [23] and as solid films [24].

The MnP-oxidation peak $(-100 \mathrm{mV})$ is slightly higher than the $\mathrm{VB} V_{\mathrm{fb}}$ value of the modified n-GaAs, lower than $-120 \mathrm{mV}$. Therefore, the lowering in the modified SC $V_{\mathrm{fb}}$, associated with $\mathrm{MnP} /$ Polysiloxane, is very important. This allows the holes, generated in the accumulation region of the $\mathrm{VB}$, to transfer upward to the $\mathrm{Mn}^{\mathrm{II}} \mathrm{P}$ ion which will give
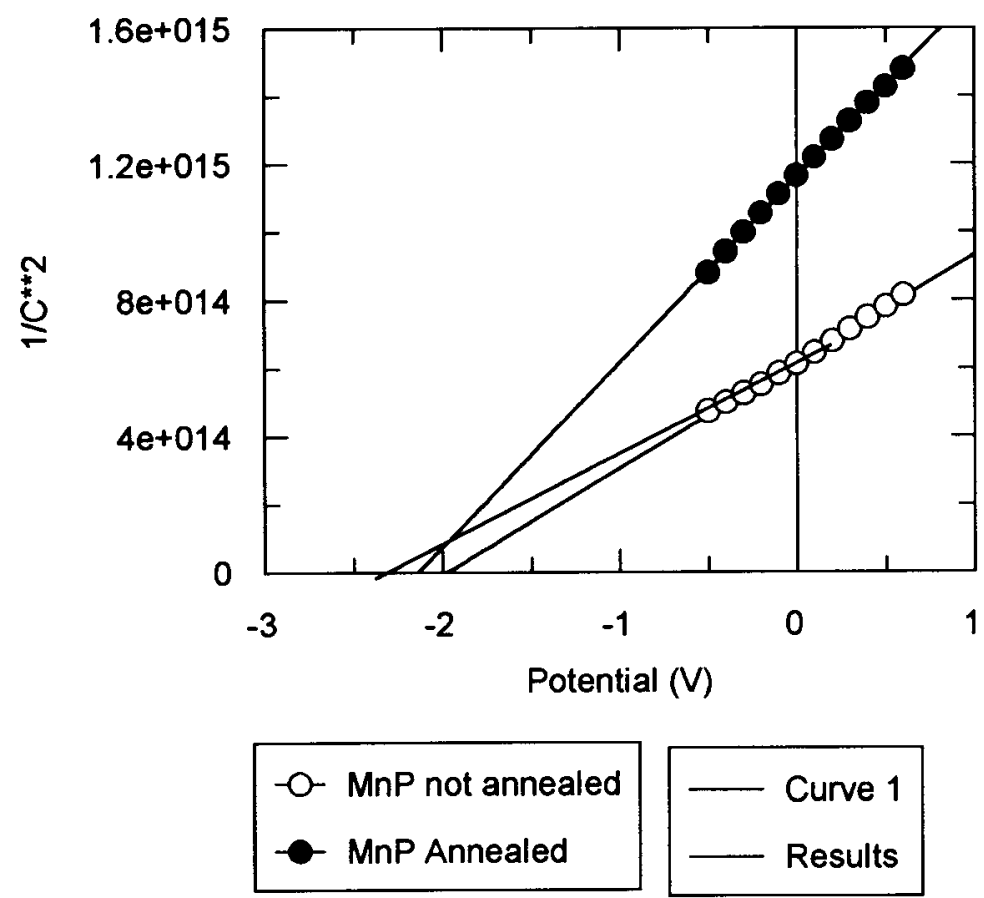

FIGURE 5 Effect of annealing the MnP/polymer-modified n-GaAs electrodes in Mott-Schottky plots under room light. Plot (a) for the annealed electrode shows a better and more linear than plot (b) with no annealing. All measurements were conducted in water $/ \mathrm{LiClO}_{4} / \mathrm{Fe}(\mathrm{CN})_{6}^{3-} / \mathrm{Fe}(\mathrm{CN})_{6}^{4-}$ at $25^{\circ} \mathrm{C}$. 
$\mathrm{Mn}^{\mathrm{III}} \mathrm{P}$. The $\mathrm{Mn}^{\mathrm{III}} \mathrm{P}$ in turn may relay the positive charge to the solution redox couple. In this way the MnP couple behaves as a charge transfer catalyst between the SC surface and the redox couple. This behavior will facilitate the charge transfer and will yield better currentpotential plots (under illumination). The study of mode of action of MnP/Polysiloxane matrix in enhancing the n-GaAs stability and efficiency in PEC light conversions is underway in these laboratories.

\section{CONCLUSIONS}

Modification of n-GaAs surfaces with MnP/Polysiloxane improved the SC characteristics at the solid liquid interface in PEC experiments in many aspects. The modified n-GaAs SC showed well-defined J-V plots in the dark and under illumination. The values of the onset potential (in the dark) and the open-circuit potential (under illumination) were shifted towards more positive values by modification with MnP. Mott-Schottky plots, measured in the dark and under illumination, for $\mathrm{n}-\mathrm{GaAs}$ were enhanced and gave accurate doping density measurements by modification. n-GaAs flat-band potential values were shifted towards more positive positions by modification. The polymer layer adhered perfectly to the semiconductor surface without peeling out. The modified SC surface enhancement was more pronounced when annealed.

\section{Acknowledgements}

This work has been conducted wholly in the laboratories of An-Najah N. University. Financial supports from An-Najah N. University, the Third World Academy of Sciences and from the Union of Arab Universities are acknowledged. The authors wish to thank Dr. J.A. Turner, of the NREL, for helpful discussions.

\section{References}

[1] Hollman, L., Hallais, J. P. and Price, J. C. (1980). In: Kaldis, E. (Ed.), Current Topics in Materials Science, Vol. 5. North Holland Publ. Co., p. 1.

[2] Frese, K. W. Jr. (1988). In: Finklea, H. (Ed.), Semiconductor Electrodes. Elsevier, Amsterdam, p. 373.

[3] Kocha, S. S., Peterson, M., Hilal, H. S., Arent, D. and Turner, J. A. (1994). In: Proc. 1994 DOE/NREL Hydrogen Program Rev., Livermore, CA., April 18-21.

[4] Kocha, S. S. and Turner, J. A. (1995). J. Electrochem. Soc., 142, 2625.

[5] Kocha, S. S. and Turner, J. A. (1996). Electrochim. Acta, 41, 1296.

[6] Frank, A. J. (1983). In: Graetzel, M. (Ed.), Energy Resources through Photochemistry and Catalysis. Academic Press, N.Y., p. 467.

[7] Frank, A. J. and Honda, K. (1982). J. Phys. Chem., 86, 1933.

[8] Hilal, H. S., Kim, C. and Schreiner, A. F. (1991). J. Mol. Catal., 64, 133; (1991). Inorg. Chim. Acta, 189, L141.

[9] Bansal, A., Tan, M. X., Tufts, B. J. and Lewis, N. S. (1993). J. Phys. Chem., 97, 7309.

[10] Harriman, A. and Porter, G. (1979). J. Chem. Soc. Faraday Trans., II, 1532.

[11] Noufi, R., Frank, A. J. and Nozik, A. J. (1981). J. Am. Chem. Soc., 103, 1849.

[12] Noufi, R., Tench, D. and Warren, L. F. (1981). J. Electrochem. Soc., 128, 2596.

[13] Frank, A. J. (1982). Mol. Cryst. Liq. Cryst., 83, 341.

[14] Frank, A. J., Glenis, S. and Nelson, A. J. (1989). J. Phys. Chem., 93, 3818.

[15] Fu-Jann Pern and Frank, A. J. (1990). J. Electrochem. Soc., 137, 2769.

[16] Glenis, S. and Frank, A. J. (1989). Synth. Met., 28, C681.

[17] Noufi, R., Frank, A. J., White, J. and Warren, L. F. (1982). J. Electrochem. Soc., 120, 2261.

[18] Kocha, S. S., Turner, J. A. and Nozik, A. J. (1994). J. Electrochem. Soc., 367, 27.

[19] Allongue, P., Cochet, H. and Horowitz, G. (1983). J. Electrochem. Soc., 130, 2352.

[20] Turner, J. A. (1983). J. Chem. Edu., 16, 327.

[21] Rajeshwar, K., Singh, P. and DuBow, J. (1978). Electrochim. Acta, 23, 1117. 
[22] Nozik, A. J. (1980). In: Gordon, F., Gomes, W. P. and Dekeyser, W. (Eds.), Photovoltaic and Phoptoelectrochemical Solar Energy Conversion. Plenum Press, N.Y., p. 297.

[23] Schultz, F. A. (1993). In: Pombeiro, A. J. L. and McCleverty, J. A. (Eds.), Molecular Electrochemistry of Inorganic, Bioorganic and Organometallic Compounds. Kluwer Acad. Publ., p. 179; Kadish, K. M. (1986). In: Lippard, S. J. (Ed.), Progress in Inorganic Chemistry, Vol. 34. J. Wiley, N.Y., p. 435.

[24] Hilal, H. S., Frank, A. J. and Turner, J. A. (unpublished data). 

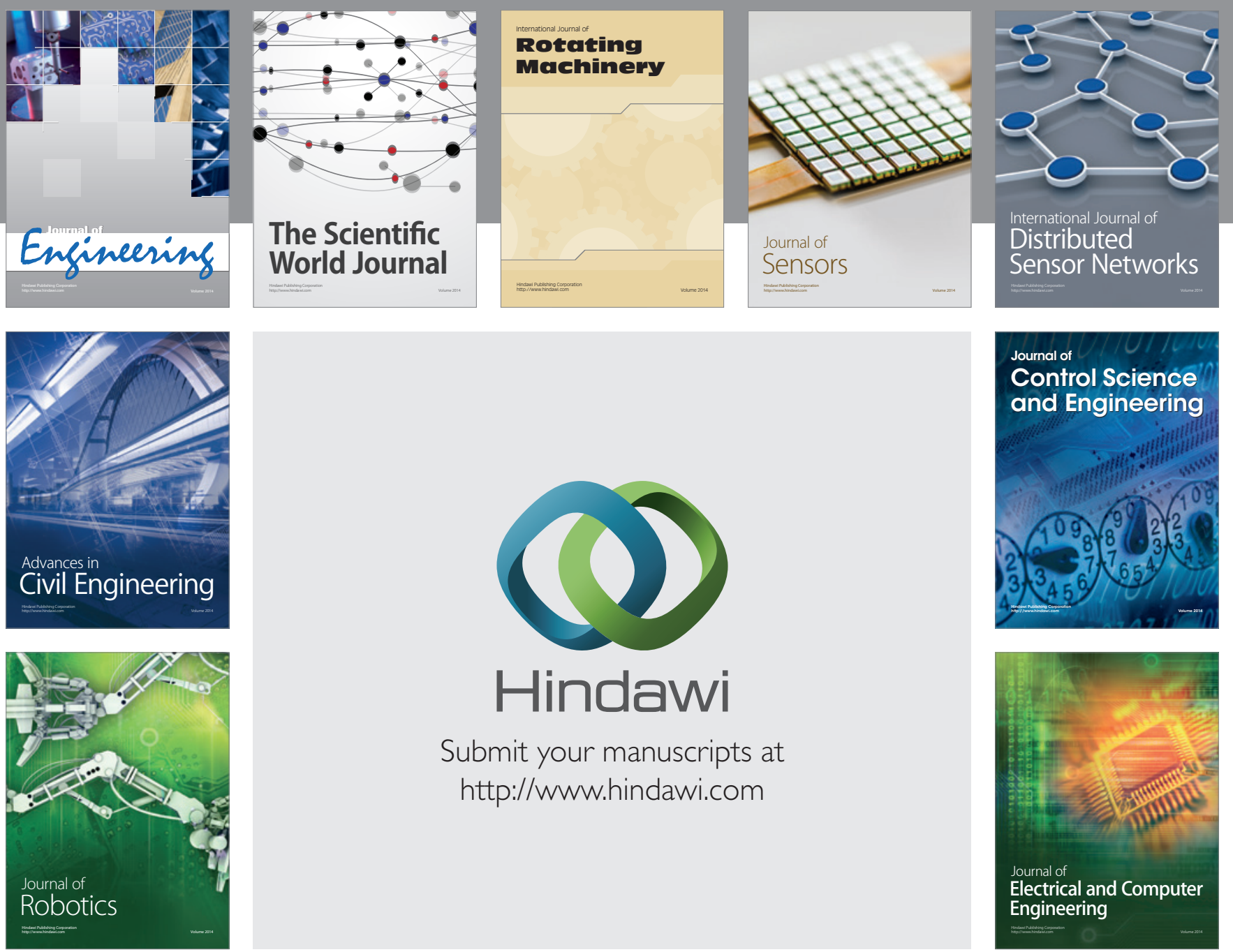

Submit your manuscripts at

http://www.hindawi.com
